Lingua e Literatura, $\mathrm{n}^{\circ}$ 24, p. 149-159. 1998.

\title{
O IMBRÓGLIO GADDIANO
}

\author{
Mariarosaria Fabris*
}

RESUMO: $O$ pastiche plurilingüistico que caracteriza Quer Pasticciaccio Brutto de Via Merulana não está presente na traduçāo brasileira. Desse modo, também o critério de montagem dos vários niveis de realidade, que preside esse romance de Carlo Emilio Gadda, acaba sendo prejudicado.

Palauras-chave: literatura italiana moderna, Carlo Emilio Gadda, romance, pastiche plurilingüistico, tradução.

Entre 1945 e 1946, Carlo Emilio Gadda escrevia uma das obras mais importantes da literatura italiana de todos os tempos: Quer Pasticciaccio Brutto de Via Merulana. Publicada primeiramente na revista Letteratura (nos números 26 a 31 , entre janeiro e dezembro de 1946), foi apresentada pela editora Garzanti em sua forma definitiva só em 1957

Do ponto de vista literário, o romance chamava a atenção por ser um policial que frustrava as expectativas dos leitores. Mas, era mesmo um policial?

Segundo o escritor Leonardo Sciascia, num pais católico como a Itália não pode haver romance policial porque este gênero literário "pressupõe uma metafísica: a existência de Deus, da Graça - da Graça que os teólogos chamam Reveladora", o que seria uma heresia. Além disso, o

(*) Professora de Língua Italiana do Departamento de Letras Modernas, FFLCH-USP. 
detetive deveria ser "o portador da Graça Reveladora” e para Gadda não é dado ao homem conhecer a origem de seu mal nem achar uma soluçāo por mais que a busque. Por isso, se encontra perdido num emaranhado do qual não consegue sair, pois sair significaria ordenar as coisas, e na Itália, novamente segundo Sciascia (desta vez à luz de Borges), "a idéia de ordem evoca a desordem mais profunda: haja visto o fascismo"

É sempre com sarcasmo e ironia que, em Quer Pasticciaccio Brutto de Via Merulana, Gadda se refere ao fascismo e principalmente a Mussolini, demonstrando abertamente seus sentimentos com relação àquele regime político, com o qual havia simpatizado num primeiro momento.

Testa di Morto (Caveira), Pupazzo (Fantoche), Facciaferoce (Cara-Brava), Somaro (Burro), Quer Tale (o Dito Cujo), chillo fetente d'o balcone 'e Palazzo Chigge (aquele mau-caráter do balcão de Palácio Chiggi), fondatore dell'impero quinquennale (fundador do império qüinqüenal), Artefice de li nuovi destini de la patria (Artifice dos novos destinos da pátria) são alguns dos epítetos usados para designar o duce, sendo que mesmo esse termo pode aparecer foneticamente deformado em truce (truculento) e buce ou bucio (provavelmente formas abreviadas da palavra romana ou napolitana bucefalo, que em italiano corresponde a bicefalo, monstro de duas cabeças) ${ }^{1}$

A maioria dos epítetos aparece em dialeto (romano ou napolitano, via de regra) não só porque são a expressão de um sentimento popular e mais generalizado, mas também porque na lingua padrão não se revestiriam do mesmo colorido. O duce e o fascismo são vistos como os fautores do mal, um mal que se espalha e contamina toda a sociedade, desde os dirigentes (o poder político, servido por Ingravallo e seus colegas da delegacia de Santo Stefano

(1) A tradução da maior parte dos epítetos foi tirada da versão brasileira do romance. 
del Cacco) até o povo, passando pelas camadas burguesas (sintetizadas no prédio de $\mathrm{n}^{\circ} 219$ de Via Merulana, onde acontecerão os crimes).

Para representar essa sociedade conturbada, Gadda se vale de uma Babel lingüística - aspecto estilístico mais marcante de todo o romance -, que se instaura desde suas primeiras páginas.

Já na apresentação de Francesco Ingravallo, que é o delegado encarregado de resolver os crimes de Via Merulana, o autor declara explicitamente o rumo lingüistico que tomará sua obra, a do pastiche:

"Quanno me chiammeno!... Già. Si me chiammeno a me... può sta ssicure ch'è nu guaio: quacche gliuommero... de sberretà..." diceva, contaminando napolitano, molisano, e italiano. (p. 3)

"Quando me chamam!... Pois é. Se chamam a mim... pode estar certo de que é uma embrulhada: algum rolo... para desatar..." dizia, contaminando napolitano, molisano e italiano. (p. 19)

O pastiche plurilingüístico verá alinhados lado a lado nāo só o italiano e alguns dialetos peninsulares (napolitano, molisano, romano, e mais vêneto e milanês), mas ainda uma série de palavras estrangeiras (em francês, inglês, espanhol e alemão), além de expressões em latim e em grego. O próprio italiano se apresenta em suas variaçōes: a lingua literária, a língua padrão e a língua falada em nível popular (o dialeto, em geral) coexistem para criar uma lingua imaginária que permite descrever, sem aderir, a sociedade romana do início de 1927 ano em que o fascismo começava a impor sua ditadura.

O pastiche no nivel lingüistico corresponde a uma variedade de situaçōes narrativas:

a) em alguns momentos, parece obedecer a critérios miméticos, como neste desabafo da senhoria do delegado 
Ingravallo, em que a passagem da lingua para o dialeto romano (de in parma de mano em diante), segundo Andreia Birtolon (p. 44), é indício de uma mudança no estado d'alma da personagem:

\begin{abstract}
"Una signora come me! Vedova del commendatore Antonini! Che si può dire che tutta Roma lo conosceva: e quanti lo conoscevano, lo portavano tutti in parma de mano, non dico perché fosse mio marito, bon'anima! E mo me prendono per un'affittacamere? Io affittacamere? Madonna santa, piuttosto me butto a fiume." (p. 2)
\end{abstract}

“Uma senhora como eu! Vúva do comendador Antonini! Que, podese dizer, era conhecido em toda Roma: e por todos que o conheciam, era tratado ali na palma da mão, nāo digo porque fosse meu marido, que Deus o tenha! E agora me tomam por dona de pensāo! Eu, dona de pensāo? Deus me livre, prefiro me atirar no rio." (p. 18)

b) em outros momentos, o pastiche sugere a busca de uma expressão mais veraz do caráter e da psicologia das personagens, como no interrogatório de Ines Cionini, a garota do presumivel criminoso, em que a alternância de napolitano e romano, que caracteriza os diálogos, cede lugar à língua literária quando a palavra passa ao narrador (no último parágrafo), mostrando a mudança de opiniāo dos policiais com relaçāo à moça. Se antes a encaravam como uma mulherzinha vulgar, no fim descobrem que ela nada mais é do que um ser humano acossado pela miséria, um ser marcado, mas que ainda mantém sua dignidade:

"Capisco," riprese il dottor Fiume. "Dimmi, ora: com'è, che faccia tiene, chesto Diomede? A proposito: Diomede: e il cognome?" "Er cognome suo...": la Ines abbassò gli occhi: arrossì a prender tempo: a fabbricare la settantatreesima bugia. [...]

"Embè, er cognome nun me l'ha voluto dì."

"Però doppo t'ha ditto," rincalzò Ingravallo. "Fuori il cognome." 
"Piccerè, ascolta. Nuie, ccà, è meglio pe tte... abbiamo bisogno del tuo aiuto."

"Sor commissario mio, che bisogno potete avè d'un regazzo? Lui nun ha fatto male a nissuno.

"A te si!... dal momento che t'ha raccattata il pattuglione."

“Embè, questi so' pasticci nostri: la questura nun se n'ha da incaricà: so' affari nostri."

"Ah! la questura non se n'ha da incaricà! Piccerè, tu stai sbarianno. Quello ch'ha dda fa 'a questura 'o sapimmo nuie." (...J

"Diomede, dunque... e lo sguardo del dottor Fumi ebbe la inderogabilità d'una richiesta di documenti, di carte necessarie. “Mbè, m'hanno detto che se chiama.. Diomede: Lanciani Diomede. $E$ sbottò in una sorta di pianto soffocato, sommesso. [...] Chinò il capo, che, ricadendo sul volto, i capelli aridi o impastati misero in ombre, e a momenti nascosero. Le sue spalle parvero affilarsi, ischeletrirsi, quasi, nei sussulti di un tacito singhiozzo. Si riasciugò il volto, e ul naso: con la manica. Levò il braccio: volle nascondervi il pianto, ripararvi il suo sgomento, il pudore. Una sdrucitura, all'attacco della manica, un'altra della sottostante maglietta, scoprirono il biancheggiare della spalla.

Nulla aveva piu, per celarsi, che quello strappato e scolorato avanzo d'indumento di povera. (p. 198-199, 203)

"Entendo" retomou o doutor Fumi. "Agora diga-me: como é, que cara tem esse Diomede? A propósito: Diomede: e o sobrenome?" "O sobrenome dele...": a Ines baixou os olhos: corou para ganhar tempo: para fabricar a septuagésima terceira mentira. [...]

"Bem, o sobrenome ele não quis me dizer."

"Porém, depois ele lhe disse" reforçou Ingravallo. "Vá despejando o sobrenome.

"Escute, guria. Cá entre nós, é melhor pra você... precisamos da sua ajuda."

"Seu delegado, que precisāo podem ter de um moço? Ele nāo fez mal a ninguém.

"Fez a você!... visto que vocè foi detida pela patrulha." 
"Bem, isso é rolo nosso: a delegacia nāo vai querer se meter nisso: sāo negócios nossos.

"Ah! a delegacia nāo vai querer se meter nisso! Guria, você está muito enganada. Nós é que sabemos o que a delegacia deve fazer." $\mid . . .1$

"Diomede, portanto... e o olhar do doutor Fumi assumiu a inderrogabilidade de uma exigència de documentos, de papéis necessários.

"Pois bem, me disseram que se chama... Diomede: Diomede Lanciani." E desatou numa espécie de choro sufocado, submisso. [...]

Baixou a cabeça, que, caindo sobre o rosto, os cabelos ásperos ou empastados sombrearam, por um momento esconderam. Seus ombros pareceram afinar-se, definhar, quase, nos estremecimentos de um silencioso soluço. Enxugou o rosto e o nariz: com a manga. Levantou o braço: quis esconder o choro, proteger sua angústia, o pudor. Um rasgāo na costura da manga, outro na camiseta de baixo descobriram a brancura do ombro. Nada mais tinha para cobrir-se a nāo ser aquele trapo rasgado e desbotado de uma roupa de pobre. (p. 170-171, 174)

c) algumas vezes, o pastiche serve para quebrar a univocidade do padrāo lingüístico, como neste trecho em que, das reflexōes de Francesco Ingravallo sobre Liliana Balducci, uma das vitima do assassino, passamos para os comentários do povo sobre a riqueza dos moradores do prédio, sobretudo do casal Balducci e da condessa Menegazzi, em cujo apartamento se dá o primeiro crime, o furto. $\mathrm{Na}$ tensão entre língua e dialeto, este acaba por contaminar toda a escrita. A descrição, graças ao emprego do discurso indireto livre, transforma-se no diz-que-diz popular do qual o delegado Ingravallo - ou o autor, uma vez que no romance é constante a mudança de narrador - se torna o porta-voz, o que justifica o fato de, no meio do romano, se insinuar o napolitano (ce steva na signora, na contessa, che teneva nu sacco 'e solde pure essa, na vedova): 
Ma lei era ancora più ricca per conto suo. Già in quer gran palazzo der ducentodicinnove nun ce staveno che signori grossi: quarche famija der generone: ma soprattutto signori novi de commercio, de quelli che un po' d'anni avanti li chiamaveno ancora pescicani. E il palazzo, poi, la gente der popolo lo chiamaveno er palazzo dell'oro. Perché tutto er casamento insino ar tetto era come imbottito de quer metallo. Drento poi, c'ereno du scale, A e B, co sei pianie co dodici inquilini cadauna, due per piano. Ma il trionfo più granne era su la scala A, piano terzo, dove che ce staveno de qua li Balducci ch'ereno signori co li fiocchi pure loro, $e$ in faccia a li Balducci ce steva na signora, na contessa, che teneva nu sacco 'e solde pure essa, na vedova: la signora Menecacci: che a cacciaje na mano in quarziasi posto ne veniva fori oro, perle, diamanti: tutta la robba più de valore che ce sia. (p. 6-7)

Mas ela, no que lhe tocava, era ainda mais rica. Pois nesse grande casarāo, no 219, só havia gente cheia da nota: algumas famúlias do generone: mas principalmente novos magnatas do comércio, desses que alguns anos atrás ainda eram chamados de tubarōes. E o casarāo, entāo, era chamado de palácio de ouro pela gente do povo. Porque todo o prédio, até o telhado, parecia forrado daquele metal. Lá dentro havia duas escadarias, A e B, com seis andares e doze inquilinos cada uma, dois por andar. Mas o triunfo maior ficava na escada $A$, terceiro andar, onde de um lado moravam os Balducci que eram ricaços dos bons, e na frente dos Balducci vivia uma senhora, uma condessa, com a burra cheia de dinheiro. uma viúva: a senhora Menecacci: que, quando punha a mão em algum lugar, fazia aparecer ouro, pérolas, brilhantes: tudo coisas das mais caras que existem. (p. 21)

d) outras vezes, o pastiche resume o critério de montagem - não só lingüistica, mas dos vários niveis de realidade, como sugere Julia Marchetti Polinesio (p. 98) - que preside toda a obra, como na descrição da perturbação de um velho guarda-linhas ao lhe comunicarem que sua so- 


\section{brinha, Camilla Mattonari (a quem o ladrāo confiara as jóias roubadas), havia sido intimada a depor:}

Il vecchietto, in realtà, nell'udire una voce sconosciuta veniva preso dal panico. Al telefono, spiegò dura la ragazza, ove non si trattasse di chiamate o di comunicazioni di servizio, era infallantemente colto da paralisi del basioglosso, lei disse che je se fermava la lingua: come un ingegnere poco incline all'oratoria che manouri perfettamente i suoi abachi e tuttavia non disponga "di parole abbastanza appropriate" nonché di sufficienti verbi italiani da poter petrarcheggiare sulle notizie poco buone. Una tipica aphasia coram telephono, reverenza, dispetto, incapacità di esprimersi in lingua, e il dubbio e anzi l'ossedente certezza di poter essere ascoltati e naturalmente scorbacchiati da terzi, da ignoti imbecilli, $e$ in definitiva lo smarrimento della personalità propria e lo spappolamento del logos in una rubefatta balbuzie, serpeggiava o stagnava endemica in Europa e però nella penisola italiana a quegli anni, di téléphone avec la manivelle. (p. 290)

O velhote, na realidade, ao ouvir uma voz desconhecida, entrara em pânico. Ao telefone, explicou a moça com dureza, quando não se tratava de chamadas ou de ligaçōes de serviço, era tomado por uma paralisia do basioglosso, que lhe travava a lingua, segundo ela: como um engenheiro pouco dado à oratória que manuseie perfeitamente seus ábacos e ao mesmo tempo não disponha de "palauras suficientemente apropriadas" e também de verbos italianos o bastante para poder petrarquear sobre as noticias menos boas. Uma típica aphasia coram telephono, reverència, despeito, incapacidade de exprimir-se na língua e a dúvida, a certeza obsessiva aliás, de poder estar sendo ouvido e naturalmente ridicularizado por terceiros, por imbecis desconhecidos, e, em suma, a perda da própria personalidade e o empastamento do logos numa rubefeita balbúcie serpejava ou estagnava endèmica na Europa e também na península itálica naqueles tempos, de téléphone avec la manivelle. (p. 242) 
Nesse último trecho, o pastiche plurilingüistico parece atingir seu ápice ao misturar língua padrão e língua literária (por exemplo: as conjunçōes ove, com valor de qualora $=$ quando, e però, com valor de perciò = portanto; o advérbio erudito infallantemente e os adjetivos raros ossedente $\mathrm{e}$ scorbacchiato em vez de infallibilmente, ossessionante e schernito, respectivamente), linguagem popular (a forma dialetal em je se fermava la lingua) e linguagens específicas (à filosofia grega clássica pede emprestada a palavra logos e à medicina, basioglosso e aphasia), além de termos e expressōes em grego (aphasia e a grafia de telephono), latim (coram) e francês (téléphone avec la manivelle).

É um dos momentos em que se torna mais patente a filiação gaddiana à corrente dantesca da literatura italiana, em oposição ao "unilingüismo petrarquesco" (e é interessante notar que o autor emprega sintomaticamente o verbo petrarcheggiare $=$ petrarquizar para significar o dominio da lingua padrão), isto é, "aquela língua absoluta e quase a-histórica em sua suprema pureza" que se perpetuou "nas escolas, nas academias, privilégio das classes conservadoras e dominantes" como havia observado Pier Paolo Pasolini (p. 314) num dos ensaios dedicados a Gadda.

$\mathrm{O}$ embaralhamento das linguagens corresponde à noção de realidade que o autor tem e nos transmite: uma meada - "nodo o groviglio, o garbuglio, o gnommero, che alla romana vuol dire gomitolo"2 - cujo fio nāo se consegue encontrar. Isso explica em parte por que, embora aparentemente o romance se estruture como um policial (de fato, há dois crimes e as diligências para descobrir o criminoso), quando nos aproximamos da solução do caso, o autor nāo satisfaz nossa curiosidade. Gadda não está interessado em apontar um culpado, nāo há culpado: o que ele quer nos mostrar - através da investigação policial ou, se qui-

(2) Tradução: "nó ou trama, garabulho ou gnommero, que em romano quer dizer novelo" (Gadda, 1990, p. 18). 
sermos, da sondagem psicológica - é como, ao viver num periodo historicamente marcado pela violência e pela irracionalidade, toda a sociedade se deixa contaminar.

O imbróglio das açōes, portanto, só poderia ser expresso pelo pastiche lingüistico. Mas, o que sobrou do plurilingüismo gaddiano na versão brasileira de seu romance Aquela Confusão Louca da Via Merulana-da qual nos servimos para traduzir os exemplos apresentados? Bem pouco, pois, como o leitor terá observado, através da opção pelo registro único, nāo foi só o colorido dos dialetos que se perdeu, mas muitas nuanças da própria língua literária que os tradutores nem sempre puderam ou souberam expressar em português. A tradução é problemática - como não poderia deixar de ser, dada a complexidade da obra desde o titulo, em que a perda maior é a reduçāo do significado do termo pasticcio (pastiche e confusāo), ainda mais se observarmos que este, em italiano, aparece na sua forma aumentativa com valor depreciativo, pasticciaccio. Os tradutores estão cientes das dificuldades que o texto apresenta, mas essa consciência se ofusca quando, para se justificarem, transformam o conteúdo no aspecto central da obra:

"O que nāo foi possivel recuperar na traduçāo foi o efeito do uso dos dialetos. $O$ texto perdeu em sutileza de caracterizaçāo $e$ coqueterie metalingüistica (embora, quem sabe, tenha ganho em inteligibilidade) e, o que é mais grave, justamente na expressāo do pólo primordial, visto ser o dialeto o veículo privilegiado por Gadda para representar a vulgaridade da vida em sua verdade mais visceral"3.

Em 1959, ao levar para a tela a adaptação do romance intitulado Un Maledetto Imbroglio, o diretor Pietro Germi fazia com que os intêrpretes só se exprimissem na lingua padrão,

(3) A. F. Bernardini. "Prefácio", in Gadda, 1990, p. 8. 
confiando a que deveria ser a expressão em romano das personagens populares à música-tema Si no me moro, numa operação parecida à empreendida pelos tradutores, que, ao reduzirem a mimese lingüistica dos dialetos a alguns termos em giria, acabaram depauperando o universo gaddiano.

\section{BIBLIOGRAFIA}

BIRTOLON, A. Proposta per una Nuova Classificazione del Linguaggio del Pasticciaccio. In: GNERRE M. et alii (org). Storia Linguistica dell'Italia nel Novecento. Roma, Bulzoni, 1973, p. 41-46.

GADDA, C. E. Aquela Confusão Louca da Via Merulana. Tradução de Aurora Fornoni Bernardini \& Homero Freitas de Andrade. Rio de Janeiro, Record, 1990.

- Quer Pasticciaccio Brutto de Via Merulana. Milano, Garzanti, 1976.

PASOLINI, P P Le Novelle dal Ducato in Fiamme, e Il Pasticciaccio. In: Passione e Ideologia. Milano, Garzanti, 1973. p. 313-318 e 318-324.

POLINESIO, J. M. A Linguagem de "Quer Pasticciaccio Brutto de Via Merulana" de Carlo Emilio Gadda. Boletim $n^{\circ}$ 32, São Paulo, FFLCH/USP 1980.

SCIASCIA, L. Il mio Contesto. L'Espresso, Roma, XXXV(5051), 24 dic. 1989. p. 194.

ABSTRACT: The linguistical pasticcio that distinguishes Quer Pasticciaccio Brutto de Via Merulana disappears in the Brazilian translation. This prejudices also the principle of assemblage among the various levels of reality that prevails over this Carlo Emilio Gadda's novel.

Keywords: modern Italian literature, Carlo Emilio Gadda, novel, linguistical pasticcio, translation. 